\title{
Efficacy of Bilberry and Grape Seed Extract Supplement Interventions to Improve Glucose and Cholesterol Metabolism and Blood Pressure in Different Populations-A Systematic Review of the Literature
}

\author{
Teresa Grohmann ${ }^{1}$, Caroline Litts ${ }^{1,2,+}$, Graham Horgan ${ }^{3}{ }^{1}$, Xuguang Zhang ${ }^{4}$, Nigel Hoggard ${ }^{1}$, Wendy Russell ${ }^{1}$ \\ and Baukje de $\operatorname{Roos}{ }^{1, *(D)}$
}

check for

updates

Citation: Grohmann, T.; Litts, C.; Horgan, G.; Zhang, X.; Hoggard, N.; Russell, W.; de Roos, B. Efficacy of Bilberry and Grape Seed Extract Supplement Interventions to Improve Glucose and Cholesterol Metabolism and Blood Pressure in Different Populations-A Systematic Review of the Literature. Nutrients 2021, 13, 1692. https://doi.org/10.3390/ nu13051692

Academic Editor: Herminia González-Navarro

Received: 30 March 2021

Accepted: 7 May 2021

Published: 17 May 2021

Publisher's Note: MDPI stays neutral with regard to jurisdictional claims in published maps and institutional affiliations.

Copyright: (C) 2021 by the authors Licensee MDPI, Basel, Switzerland. This article is an open access article distributed under the terms and conditions of the Creative Commons Attribution (CC BY) license (https:/ / creativecommons.org/licenses/by/ $4.0 /)$.
1 Rowett Institute, University of Aberdeen, Foresterhill, Aberdeen AB25 2ZD, UK; t.grohmann@abdn.ac.uk (T.G.); c.litts@rgu.ac.uk (C.L.); n.hoggard@abdn.ac.uk (N.H.); w.russell@abdn.ac.uk (W.R.)

2 Formerly Rowett Institute, University of Aberdeen, Aberdeen AB25 2ZD, UK

3 Biomathematics \& Statistics Scotland, Aberdeen AB25 2ZD, UK; g.horgan@abdn.ac.uk

4 By-Health Ltd. Co, No.3 Kehui 3rd Street, No.99 Kexue Avenue Central, Luogang District, Guangzhou 510000, China; zhangxg2@by-health.com

* Correspondence: b.deroos@abdn.ac.uk

† Formerly Rowett Institute, now affiliated with Robert Gordon University.

Abstract: Intervention with fruit extracts may lower glucose and lipid levels, as well as blood pressure. We reviewed the efficacy of bilberry and grape seed extracts to affect these outcomes across populations with varying health status, age and ethnicity, across intervention doses and durations, in 24 intervention studies with bilberry and blackcurrant $(n=4)$ and grape seed extract $(n=20)$. Bilberry and blackcurrant extract lowered average levels of glycated hemoglobin (HbA1c), at least in Chinese subjects, especially in those who were older, who were diagnosed with Type 2 Diabetes Mellitus (T2DM) and who were participating in longer-term studies. We also found good evidence that across studies and in subjects with hypercholesterolemia, T2DM or metabolic syndrome, intervention with bilberry and blackcurrant extract, and to some extent grape seed extract, significantly lowered total and low density lipoprotein (LDL) cholesterol levels after four weeks. Intervention with grape seed extract may reduce systolic and diastolic blood pressure in subjects with hypertension or metabolic syndrome. Differential responsiveness in cholesterol and blood pressure outcomes between stratified populations could not be explained by age, dose or study duration. In conclusion, bilberry and blackcurrant extract appears effective in lowering HbA1c and total and LDL cholesterol, whereas grape seed extract may lower total and LDL cholesterol, and blood pressure, in specific population groups.

Keywords: bilberry; grape seed; extracts; glucose; cholesterol; blood pressure; human intervention studies

\section{Introduction}

In 2014,422 million people, nearly $8.5 \%$ of the world's population, were diagnosed with Type 2 Diabetes Mellitus (T2DM). Within 20 years, this number is expected to double, increasing the burden on healthcare systems, partly because of increased co-morbidities such as cardiovascular diseases (CVD) [1].

Daily consumption of fruits and green leafy vegetables can reduce T2DM risk and improve metabolic health outcomes [2]. Increasing evidence also suggests that fruit extracts may help prevent the onset of diabetes, possibly due to their flavonoid content including flavan-3-ols and anthocyanins [3]. Anthocyanins complexed with sugar moieties, such as rutinoside, and polymeric flavan-3-ols, represent a major proportion of flavonoids in fruits $[4,5]$. Many of these compounds have been found to transit the small intestine intact, 
after which they can be metabolized by the colonic microbiota [6]. Whilst the bioavailability of intact dietary flavan-3-ols and anthocyanins is relatively low, microbiota-derived metabolites are absorbed more easily and circulate in plasma for significantly longer periods of time [5,6]. Therefore, it has been suggested that microbiota-derived metabolites may contribute to the anti-diabetic effects of fruit, vegetable or fruit extracts $[5,6]$.

The mechanism by which dietary flavonoids affect cardiometabolic outcomes is dependent on the concentration of flavonoids in the diet, on genetic factors that determine enzyme activity, on gut microbiota composition and on lifestyle, which all are highly individualized factors [7]; such factors tend to be overlooked in population-based studies [8]. Therefore, a more in-depth analysis of study population characteristics is required to better understand the variation in responsiveness to dietary interventions with flavonoids.

Higher dietary intakes of anthocyanins and catechins have been associated with a significantly lower risk of T2DM in 60,586 women over a 20-year observation period [9]. Bilberries are one of the richest natural sources of anthocyanins [10,11], whereas grape seeds contain the highest levels of total procyanidins and procyanidin dimers in fruits and vegetables [12]. However, previous studies evaluating the anti-diabetic and cholesterollowering effects of bilberry and grape seed extracts in humans have been inconclusive, mainly due to a large variability in outcomes within and between study populations. Often, the heterogeneity in study outcomes was not explored. A meta-analysis by Zhu et al. [13] concluded that dietary interventions with cranberries or blueberries had no effect on cholesterol levels, but intervention with whortleberry and bilberry improved cholesterol levels in subjects at risk of cardiovascular disease, and in subjects with metabolic syndrome and hypercholesterolemia. A systematic review by Woerdeman et al. [14] concluded that interventions with grape polyphenols did not significantly affect glycemia, insulin sensitivity, cholesterol levels or blood pressure, arguably due to differences in study quality, study populations and study durations. A recent meta-analysis, including meta-regression and subgroup analysis to identify sources of heterogeneity in previous reviews, concluded that intervention with grape seed extract decreased LDL cholesterol and triglycerides across studies, and LDL and total cholesterol in studies with less than 10 weeks of intervention, and in those studies providing $<300 \mathrm{mg} / \mathrm{d}$ of grape seed extract [15]. The meta-analysis by Zhang et al. [16] concluded that grape seed extracts decreased systolic and diastolic blood pressure, with effects being significantly more pronounced in subjects with metabolic syndrome and in pre-hypertensive individuals. Interestingly, intervention with grape seed extract did not affect blood pressure in hypertensive subjects, arguably due to variance in study designs and bias arising from a low sample size [16].

The aim of this critical and systematic review was to investigate the efficacy of, and responsiveness to, different doses and intervention regimes of bilberry extract and grape seed extract to improve glucose and cholesterol metabolism, and blood pressure, in different populations.

\section{Materials and Methods}

The databases Cochrane Library, Ovid Medline (Embase 1996-2021, and Ovid Medline ${ }^{\circledR}$ without revisions 1996-Week 5 2021) and Scopus were consulted up until January 2021 by two independent researchers (T.G. and C.L.). The following search terms were explored within titles, keywords and abstracts: (grape adj1 seed AND extract AND vitis adj1 vinifera) OR (bilberry AND extract AND vaccinium adj1 myrtillus) AND (human AND human adj1 study AND obes* AND Type 2 Diabetes) AND (blood adj1 glucose AND glycated $\mathrm{h}^{*}$ emoglobin AND HbA1c) OR (cholesterol) OR (systolic AND diastolic).

Studies fulfilling the following criteria were included in the review: availability of a full-text English publication of the study; studies with a long-term intervention (i.e., $\geq 4$ weeks) with bilberry and/or grape seed extract or a combination of either extract with other fruit extracts; studies executed in healthy subjects or those diagnosed with T2DM, metabolic syndrome, hypercholesterolemia or mild hypertension as classified by the authors of respective studies; studies with a randomized, placebo controlled and 
single- or double-blind design; studies measuring the following outcomes: fasting blood glucose, $\mathrm{HbA1c}$, total cholesterol, HDL and LDL cholesterol, and systolic and diastolic blood pressure. Studies using fresh or frozen fruits, fruit juices, as well as acute studies and those that had exclusively recruited smokers were excluded from this review.

The following data were extracted from the selected studies: first author name, study duration, type of extract, information on supplement formulation, intervention dose, study design (cross-over/parallel), blinding, randomization, total number of subjects, number of subjects in the intervention and placebo group, number of drop-outs, male/female ratio, age range and BMI range of subjects, health condition, the calculated average percentage change for each of the outcomes between the end of the study and baseline for the intervention and placebo groups, and reported $p$-values.

The quality of studies was evaluated using the Cochrane method for bias evaluation [17]. The PRISMA checklist was followed to ensure review quality. We calculated a Spearman correlation matrix to explore which factors, such as intervention, dose, study duration, BMI and age were correlated with specific study outcomes, such as fasting blood glucose, $\mathrm{HbA1c}$, total cholesterol, LDL and HDL cholesterol, systolic and diastolic blood pressure. The statistical and visual analysis of data was performed using R, version 4.0.2, and R Studio version 1.2.5042 [18]. The R packages used were corrplot [19] and ggplot2 [20]. No post-hoc test, such as Bonferroni, was applied to correct for the number of correlations as this may have increased the risk of introducing Type 1 errors in an exploratory analysis. Instead, we decided to set the level of significance at $p \leq 0.01$.

\section{Results}

\subsection{Study Selection}

The results of the literature search and selection process are shown in Figure 1. In total, 4167 records were obtained from the search, and four additional records were identified through reference lists from other reviews. After initially removing duplicate records $(n=2241)$ based on titles and abstracts, a further 1845 records were excluded as these did not assess interventions with bilberry or grape seed extracts, or were studies which performed in vitro or in animal models. The remaining 85 records were further analyzed for full-text availability. We identified and removed 24 records, which were conference abstracts or registered clinical trials without publications, and removed 33 duplicate records. We also excluded one record as it was not available in English, one record as it did not provide baseline and endpoint data, and two records as these were not available in full text. In total 24 studies were analyzed for this review.

\subsection{Study Characteristics}

The main characteristics of the 24 selected studies are summarized in Table 1 . The studies were performed in nine different countries. The number of volunteers per study ranged from 18 to 160 . The study participants were either healthy ( $n=3$ studies), or healthy and in different stages of menopause ( $n=2$ studies), diagnosed with T2DM ( $n=4$ studies), diagnosed with metabolic syndrome $(n=5$ studies), diagnosed with hypercholesterolemia ( $n=5$ studies), or diagnosed with mild hypertension ( $n=5$ studies). The BMI range across studies was 18 to $39 \mathrm{~kg} / \mathrm{m}^{2}$, and the age range of study participants was between 13 and 75 years. Study populations in the USA had on average the highest BMI (age: $48 \pm 4$ years, BMI: $33 \pm 3 \mathrm{~kg} / \mathrm{m}^{2}$ ), whilst study populations in Japan had on average the lowest BMI (age: $52 \pm 2$ years, BMI: $23 \pm 1 \mathrm{~kg} / \mathrm{m}^{2}$ ). The youngest study population was recruited in Iran (age: $39 \pm 15$ years, BMI: $30 \pm 4 \mathrm{~kg} / \mathrm{m}^{2}$ ). Four studies recruited only women, while two studies did not identify the subjects' sex. The majority of studies $(n=20)$ performed an intervention with grape seed extract, testing a supplement dose of $100 \mathrm{mg}$ to $1500 \mathrm{mg}$ per day. Four studies evaluated the effect of bilberry and blackcurrant extract at a dose of $320 \mathrm{mg}$ per day. The duration of the intervention period across studies ranged from 4 to 52 weeks. Four studies employed a crossover design where intervention periods lasted four to eight weeks. 


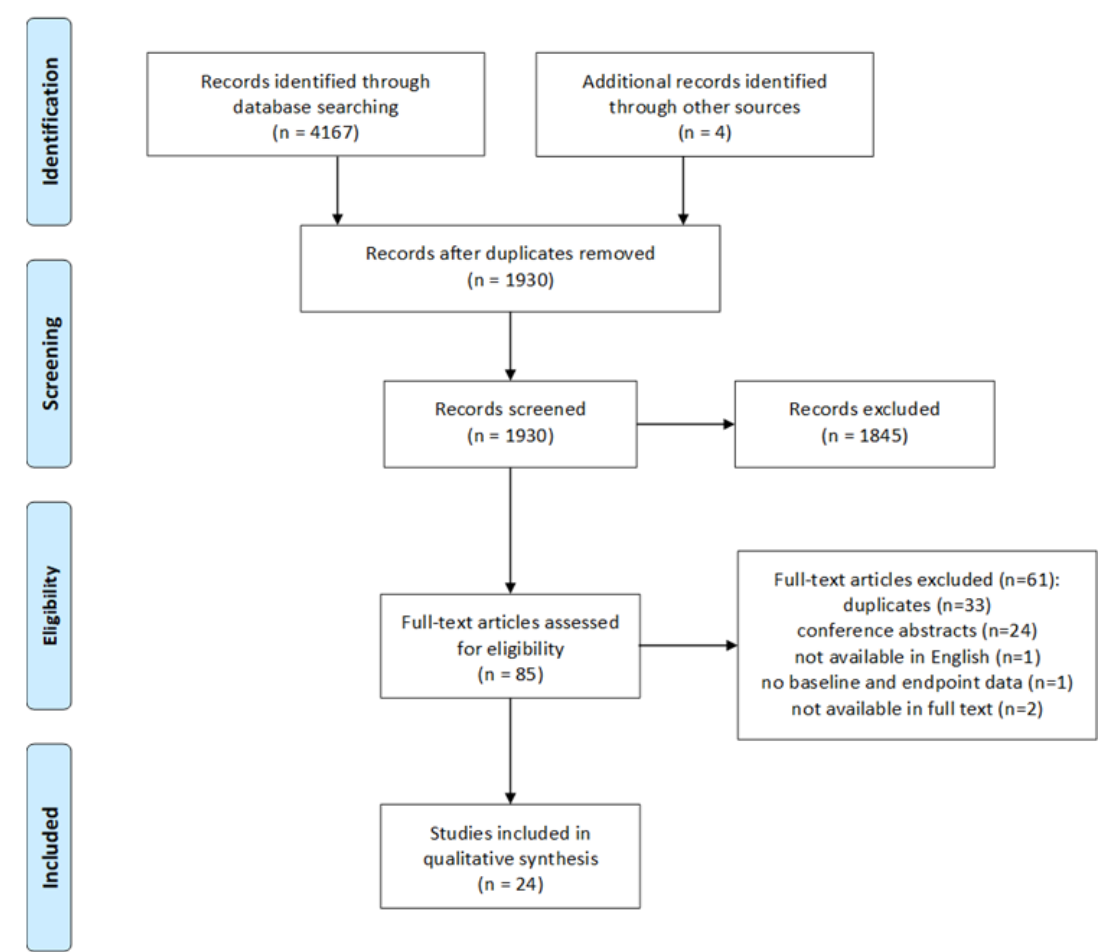

Figure 1. Process flow chart of the systematic literature search.

\subsection{Evaluation of Study and Reporting Quality}

The Cochrane bias evaluation was performed to evaluate study and reporting quality (Figure 2) [17]. The method for randomization was not described in 16 out of 24 studies, and concealment of intervention allocation was not described in half of the studies $(n=12)$. Participants and researchers were blind to the intervention sequence in most studies $(n=21)$. One study did not describe the blinding process [37], and two studies described issues which may have affected the blinding: an unequal number of capsules for the intervention and placebo [22] and blinding of researchers but not participants to the intervention sequence [23]. Two studies reported dropouts, but did not mention baseline population characteristics after dropouts [36,41]. One study only reported blood pressure outcomes for selective individuals with hypertension [28]. We detected gender imbalance between intervention and placebo groups in two studies [32,40]. In one study, baseline levels of insulin and HOMA-IR, the main outcomes in this study, were significantly different between intervention and placebo groups at baseline [32]. Two studies reported unequal participant numbers in intervention and placebo group after dropouts [36,41]. Half of the studies did not report withdrawals or dropouts; the reported drop-out rates ranged from $1 \%$ to $38 \%$ (Table 1 ).

\subsection{Correlation Analysis}

A correlation analysis of factors including study design, subject characteristics and study outcomes was performed across the 24 studies to assess whether any of these factors could explain the efficacy of the bilberry and grape seed interventions to affect glucose and cholesterol metabolism, and blood pressure, in stratified groups of volunteers (Figure 3). 
Table 1. Overview of supplement studies with grape seed or bilberry extract.

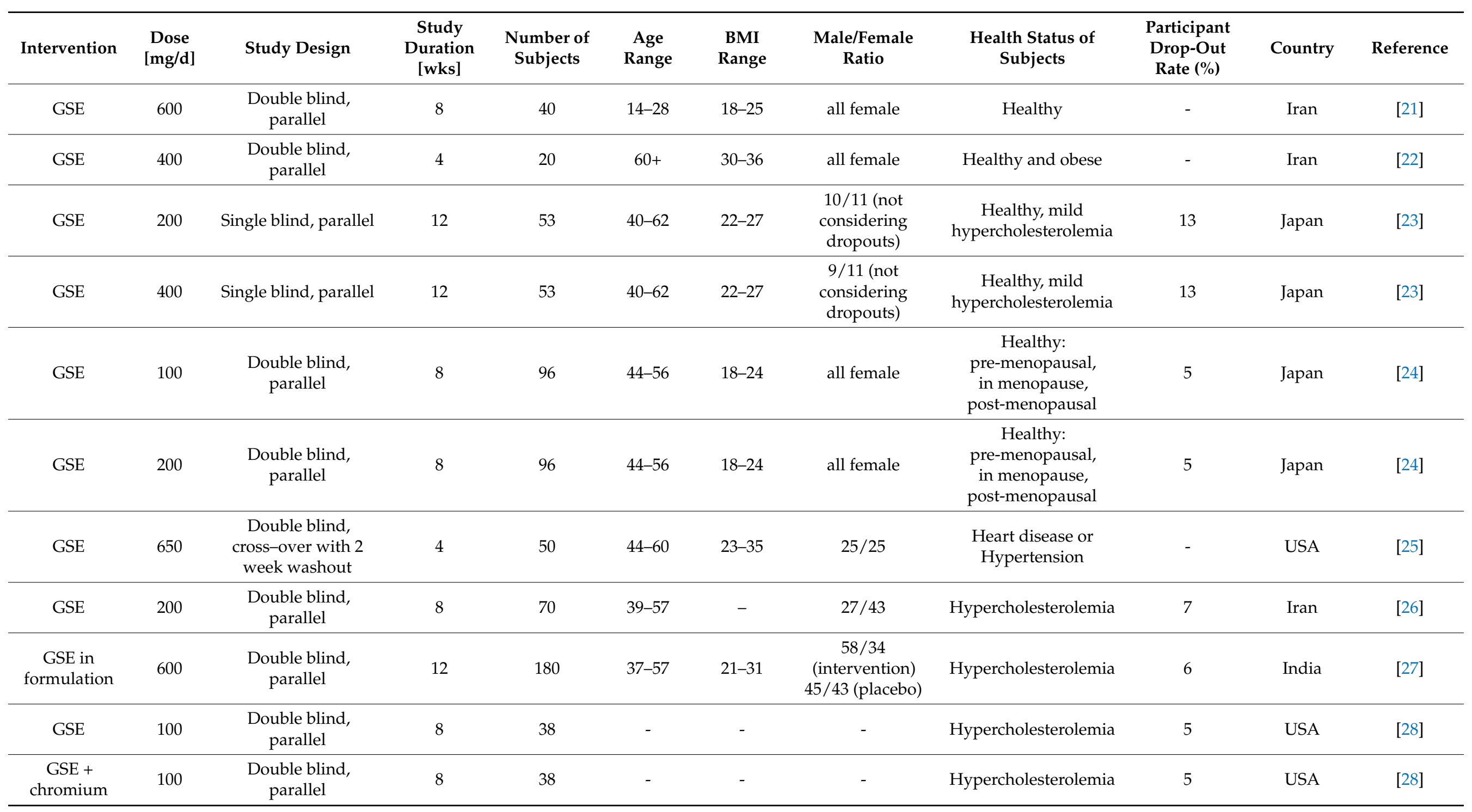


Table 1. Cont.

\begin{tabular}{|c|c|c|c|c|c|c|c|c|c|c|c|}
\hline Intervention & $\begin{array}{l}\text { Dose } \\
{[\mathrm{mg} / \mathrm{d}]}\end{array}$ & Study Design & $\begin{array}{c}\text { Study } \\
\text { Duration } \\
\text { [wks] }\end{array}$ & $\begin{array}{l}\text { Number of } \\
\text { Subjects }\end{array}$ & $\begin{array}{l}\text { Age } \\
\text { Range }\end{array}$ & $\begin{array}{l}\text { BMI } \\
\text { Range }\end{array}$ & $\begin{array}{l}\text { Male/Female } \\
\text { Ratio }\end{array}$ & $\begin{array}{l}\text { Health Status of } \\
\text { Subjects }\end{array}$ & $\begin{array}{c}\text { Participant } \\
\text { Drop-Out } \\
\text { Rate (\%) }\end{array}$ & Country & Reference \\
\hline GSE & 200 & $\begin{array}{l}\text { Double blind, } \\
\text { cross-over with } 8 \\
\text { week washout }\end{array}$ & 8 & 42 & $39-57$ & - & $18 / 24$ & Hypercholesterolemia & 19 & Iran & [29] \\
\hline $\begin{array}{c}\text { Bilberry and } \\
\text { blackcurrant } \\
\text { extract }\end{array}$ & 320 & $\begin{array}{l}\text { Double blind, } \\
\text { parallel }\end{array}$ & 24 & 146 & $40-65$ & - & $31 / 42$ & Hypercholesterolemia & 3 & China & [30] \\
\hline $\begin{array}{l}\text { GSE in } \\
\text { formulation }\end{array}$ & 540 & $\begin{array}{c}\text { Double blind, } \\
\text { cross-over with } 2 \\
\text { week washout }\end{array}$ & 4 & 18 & $41-47$ & $31-34$ & $15 / 3$ & Metabolic syndrome & 38 & USA & {$[31]$} \\
\hline GSE & 100 & $\begin{array}{l}\text { Double blind, } \\
\text { parallel }\end{array}$ & 8 & 42 & $13-19$ & $27-36$ & $\begin{array}{c}14 / 7 \\
\text { (intervention) } \\
5 / 16 \text { (placebo) }\end{array}$ & Metabolic syndrome & 13 & Iran & [32] \\
\hline $\begin{array}{c}\text { Bilberry and } \\
\text { blackcurrant } \\
\text { extract }\end{array}$ & 320 & $\begin{array}{l}\text { Double blind, } \\
\text { parallel }\end{array}$ & 12 & 120 & $40-65$ & $22-31$ & $21 / 39$ & Metabolic syndrome & - & China & [33] \\
\hline GSE & 150 & $\begin{array}{l}\text { Double blind, } \\
\text { parallel }\end{array}$ & 4 & 27 & $42-48$ & $34-37$ & $4 / 5$ & Metabolic syndrome & - & USA & [34] \\
\hline GSE & 300 & $\begin{array}{l}\text { Double blind, } \\
\text { parallel }\end{array}$ & 4 & 27 & $43-51$ & $34-39$ & $4 / 5$ & Metabolic syndrome & - & USA & {$[34]$} \\
\hline GSE & 300 & $\begin{array}{l}\text { Double blind, } \\
\text { parallel }\end{array}$ & 12 & 40 & $31-36$ & $27-39$ & $\begin{array}{c}4 / 16 \\
\text { (intervention) } \\
3 / 17 \text { (placebo) }\end{array}$ & Metabolic syndrome & 20 & Iran & [35] \\
\hline $\begin{array}{c}\text { GSE in } \\
\text { formulation }\end{array}$ & 1500 & $\begin{array}{l}\text { Double blind, } \\
\text { parallel }\end{array}$ & 52 & 131 & $58-72$ & $23-31$ & all female & Postmenopausal & 17 & Russia & [36] \\
\hline GSE & 150 & $\begin{array}{l}\text { Double blind, } \\
\text { parallel }\end{array}$ & 16 & 119 & $44-56$ & $24-26$ & $17 / 18$ & Pre-hypertension & - & Italy & [37] \\
\hline GSE & 300 & $\begin{array}{c}\text { Double blind, } \\
\text { parallel }\end{array}$ & 16 & 119 & $44-56$ & $24-26$ & $23 / 14$ & Pre-hypertension & - & Italy & [37] \\
\hline
\end{tabular}


Table 1. Cont.

\begin{tabular}{|c|c|c|c|c|c|c|c|c|c|c|c|}
\hline Intervention & $\begin{array}{l}\text { Dose } \\
{[\mathrm{mg} / \mathrm{d}]}\end{array}$ & Study Design & $\begin{array}{c}\text { Study } \\
\text { Duration } \\
\text { [wks] }\end{array}$ & $\begin{array}{l}\text { Number of } \\
\text { Subjects }\end{array}$ & $\begin{array}{l}\text { Age } \\
\text { Range }\end{array}$ & $\begin{array}{c}\text { BMI } \\
\text { Range }\end{array}$ & $\begin{array}{l}\text { Male/Female } \\
\text { Ratio }\end{array}$ & $\begin{array}{l}\text { Health Status of } \\
\text { Subjects }\end{array}$ & $\begin{array}{c}\text { Participant } \\
\text { Drop-Out } \\
\text { Rate (\%) }\end{array}$ & Country & Reference \\
\hline GSE & 200 & $\begin{array}{l}\text { Double blind, } \\
\text { parallel }\end{array}$ & 12 & 30 & $40-64$ & $19-27$ & $2 / 8$ & Pre-hypertension & - & Japan & [38] \\
\hline GSE & 400 & $\begin{array}{l}\text { Double blind, } \\
\text { parallel }\end{array}$ & 12 & 30 & $40-64$ & $19-27$ & $2 / 8$ & Pre-hypertension & - & Japan & [38] \\
\hline GSE & 300 & $\begin{array}{l}\text { Double blind, } \\
\text { parallel }\end{array}$ & 8 & 70 & $62-64$ & $18-30$ & $19 / 16$ & Pre-hypertension & 1 & $\begin{array}{l}\text { The } \\
\text { Nether- } \\
\text { lands }\end{array}$ & [39] \\
\hline GSE & 300 & $\begin{array}{l}\text { Double blind, } \\
\text { parallel }\end{array}$ & 8 & 32 & $48-57$ & - & $\begin{array}{c}9 / 7 \\
\text { (intervention) } \\
6 / 10 \text { (placebo) }\end{array}$ & Pre-hypertension & - & USA & {$[40]$} \\
\hline $\begin{array}{c}\text { Bilberry and } \\
\text { blackcurrant } \\
\text { extract }\end{array}$ & 320 & $\begin{array}{l}\text { Double blind, } \\
\text { parallel }\end{array}$ & 12 & 160 & $40-75$ & $21-28$ & $25 / 55$ & $\begin{array}{c}\text { Pre-diabetes and } \\
\text { T2DM }\end{array}$ & 14 & China & [41] \\
\hline GSE & 600 & $\begin{array}{c}\text { Double blind, } \\
\text { cross-over with } 2 \\
\text { week washout }\end{array}$ & 4 & 32 & $55-68$ & $24-36$ & $16 / 16$ & $\mathrm{~T} 2 \mathrm{DM}$ & - & UK & [42] \\
\hline $\begin{array}{c}\text { Bilberry and } \\
\text { blackcurrant } \\
\text { extract }\end{array}$ & 320 & $\begin{array}{l}\text { Double blind, } \\
\text { parallel }\end{array}$ & 24 & 58 & $56-67$ & $20-27$ & $17 / 12$ & $\mathrm{~T} 2 \mathrm{DM}$ & - & China & [43] \\
\hline GSE & 200 & $\begin{array}{l}\text { Double blind, } \\
\text { parallel }\end{array}$ & 8 & 48 & $30-65$ & $25-37$ & - & $\mathrm{T} 2 \mathrm{DM}$ & 20 & Iran & {$[44]$} \\
\hline
\end{tabular}




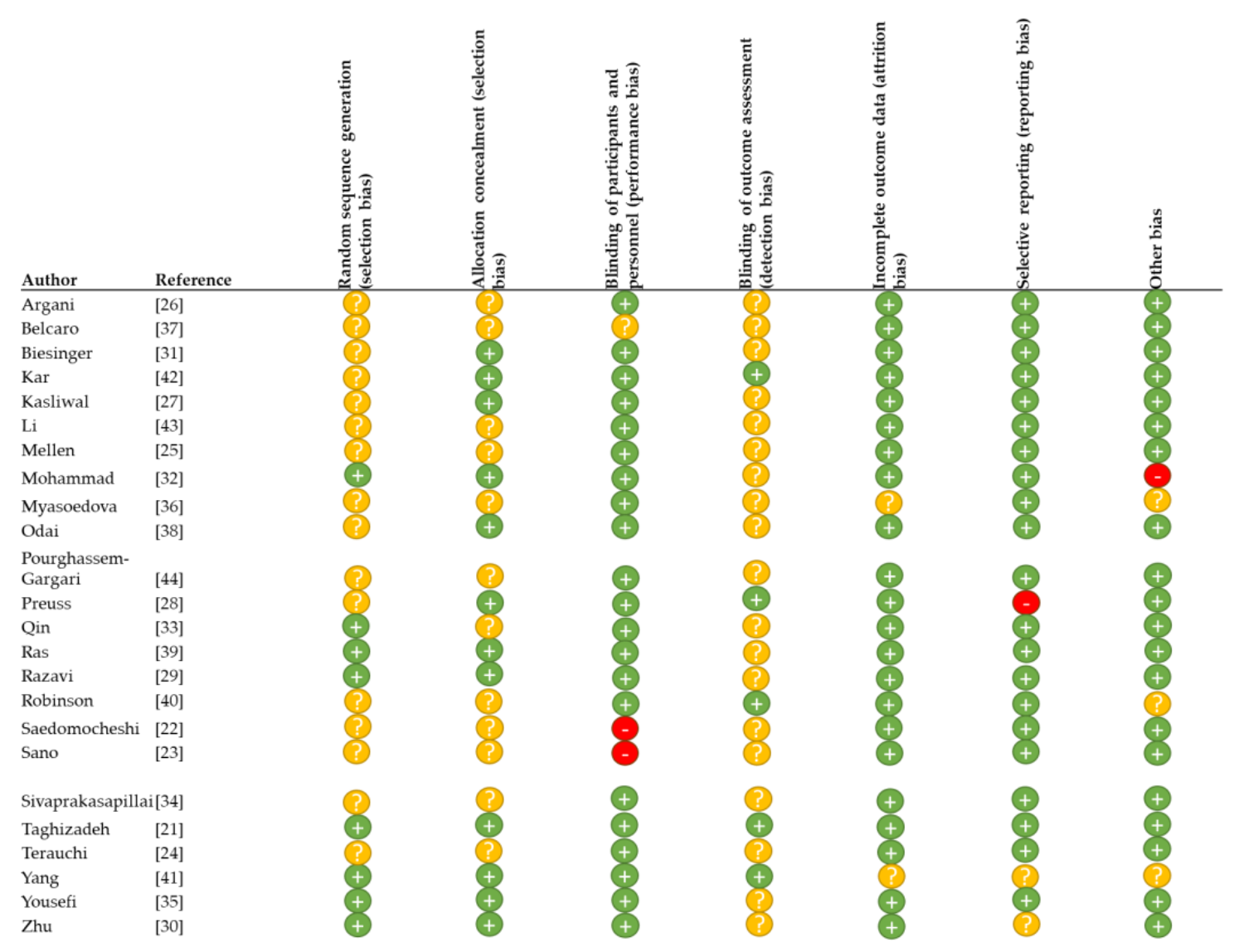

Figure 2. Cochrane evaluation of study bias; "+" low risk of bias, “?” unclear risk of bias, "-“ high risk of bias.

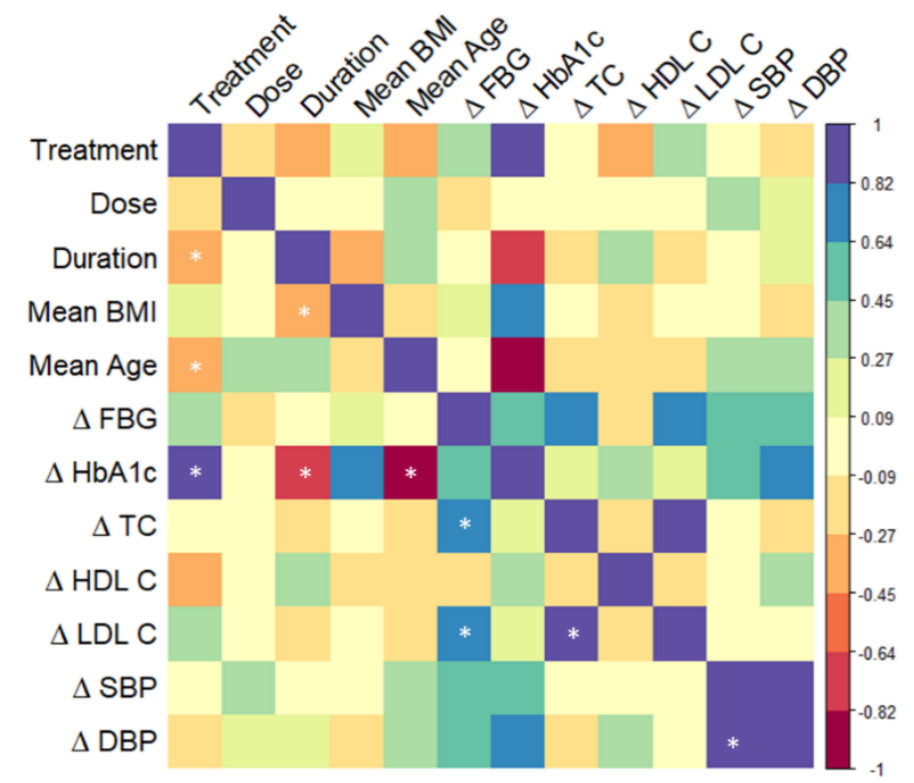

Figure 3. Correlation heatmap of study characteristics, subject characteristics and percentage change in fasting blood glucose, HbA1c, cholesterols and blood pressure levels across 24 studies. The treatments were expressed as numbers (bilberry and blackcurrant =1, grape seed $=2$ ). Mean BMI and age were calculated for each study population where reported. FBG-fasting blood glucose, HbA1c-glycated hemoglobin, TC —-total cholesterol, HDL C - high density lipoprotein cholesterol, LDL C - - low density lipoprotein cholesterol, SBP — systolic blood pressure, DBP—diastolic blood pressure. The matrix was calculated using corrplot [19] in R studio. ${ }^{*} p<0.01$. 
When considering significant correlations $(p \leq 0.01)$ across studies, we observed that average changes in $\mathrm{HbA} 1 \mathrm{c}$ levels were positively correlated with treatment $(\mathrm{R}=0.84$; $p=0.008$ ), indicating that bilberry and blackcurrant extract (treatment 1 ) may be more effective than grape seed extract (treatment 2) in lowering HbA1c levels. In addition, average changes in $\mathrm{HbA1}$ c were negatively correlated with age $(\mathrm{R}=-0.88 ; p=0.003)$, and with study duration $(\mathrm{R}=-0.69 ; p=0.005)$, indicating that larger reductions in HbA1c levels were observed in subjects who were older and participating in longer-term studies. Average changes in levels of fasting blood glucose were positively correlated with average changes in total cholesterol $(\mathrm{R}=0.78 ; p=0.007)$ and LDL cholesterol levels $(\mathrm{R}=0.7 ; p=0.002)$, suggesting that modulation of these outcomes could share common mechanistic pathways, such as those involved in increasing insulin sensitivity. Average changes in total and LDL cholesterol were positively correlated $(\mathrm{R}=0.87 ; p<0.001)$, as were average changes in systolic and diastolic blood pressure $(\mathrm{R}=0.88 ; p<0.001)$, which is to be expected, as these outcomes are physiologically linked. Furthermore, treatment was negatively correlated with study duration $(\mathrm{R}=-0.45 ; p=0.001)$ and age of subjects $(\mathrm{R}=-0.41 ; p=0.003)$, indicating differences in study design and study populations between studies with either bilberry and blackcurrant extract or grape seed extract. Study duration was also negatively correlated with average BMI $(\mathrm{R}=-0.45 ; p=0.002)$, indicating that participants with a lower BMI took part in longer-term interventions.

\subsection{Efficacy of Grape Seed or Bilberry and Blackcurrant Extract Supplements to Modulate Glucoses Metabolism}

Nine studies - six studies with grape seed extract $[21,23,25,31,32,44]$ and three studies with bilberry and blackcurrant extract $[33,41,43]$ - measured fasting blood glucose levels as an outcome. Five studies - three studies with grape seed extract $[23,27,44]$ and two studies with bilberry and blackcurrant extract $[41,43]$ - measured $\mathrm{HbA} 1 \mathrm{c}$ as an outcome. None of the studies with grape seed extract observed significant changes in levels of fasting blood glucose or $\mathrm{HbA1c}$, which may be linked to the fact that the majority of these studies were performed in healthy subjects (Figure 4). One out of three studies with bilberry and blackcurrant extract measuring fasting glucose as an outcome reported a significant reduction of $8.5 \%$ in levels of fasting blood glucose in subjects diagnosed with T2DM [43]. One out of two studies with bilberry and blackcurrant extract measuring $\mathrm{HbA} 1 \mathrm{c}$ as an outcome reported a significant decrease of $4.7 \%$ in levels of $\mathrm{HbA} 1 \mathrm{c}$ in subjects diagnosed with pre-diabetes and T2DM [41]. There was no evidence for a dose-response effect across studies with either grape seed or bilberry and blackcurrant extract (Figure 4).

\subsection{Efficacy of Grape Seed or Bilberry and Blackcurrant Extract Supplements to Modulate Cholesterol Metabolism}

Twenty studies - sixteen studies with grape seed extract and four studies with bilberry and blackcurrant extract-measured effects on cholesterol outcomes. All four bilberry and blackcurrant extract studies $[30,33,41,43]$ and five of the sixteen grape seed extract studies [26-29,35] observed significant improvements in at least one cholesterol marker. Significant reductions in total and LDL cholesterol were observed across studies, and in different study populations where subjects had been diagnosed with hypercholesterolemia, T2DM or metabolic syndrome, in those studies that lasted four weeks or longer. Longer study durations did not reduce total and LDL cholesterol further. The effect of intervention with either grape seed or bilberry and blackcurrant extract on HDL cholesterol was more variable. Only one study with grape seed extract [35], and three intervention studies with bilberry and blackcurrant extract $[30,33,43]$, showed a significant average increase in HDL cholesterol, but the response was not linked to study design or population characteristics, or other study outcomes. Dose did not affect the response in cholesterol levels (Figure 5). 

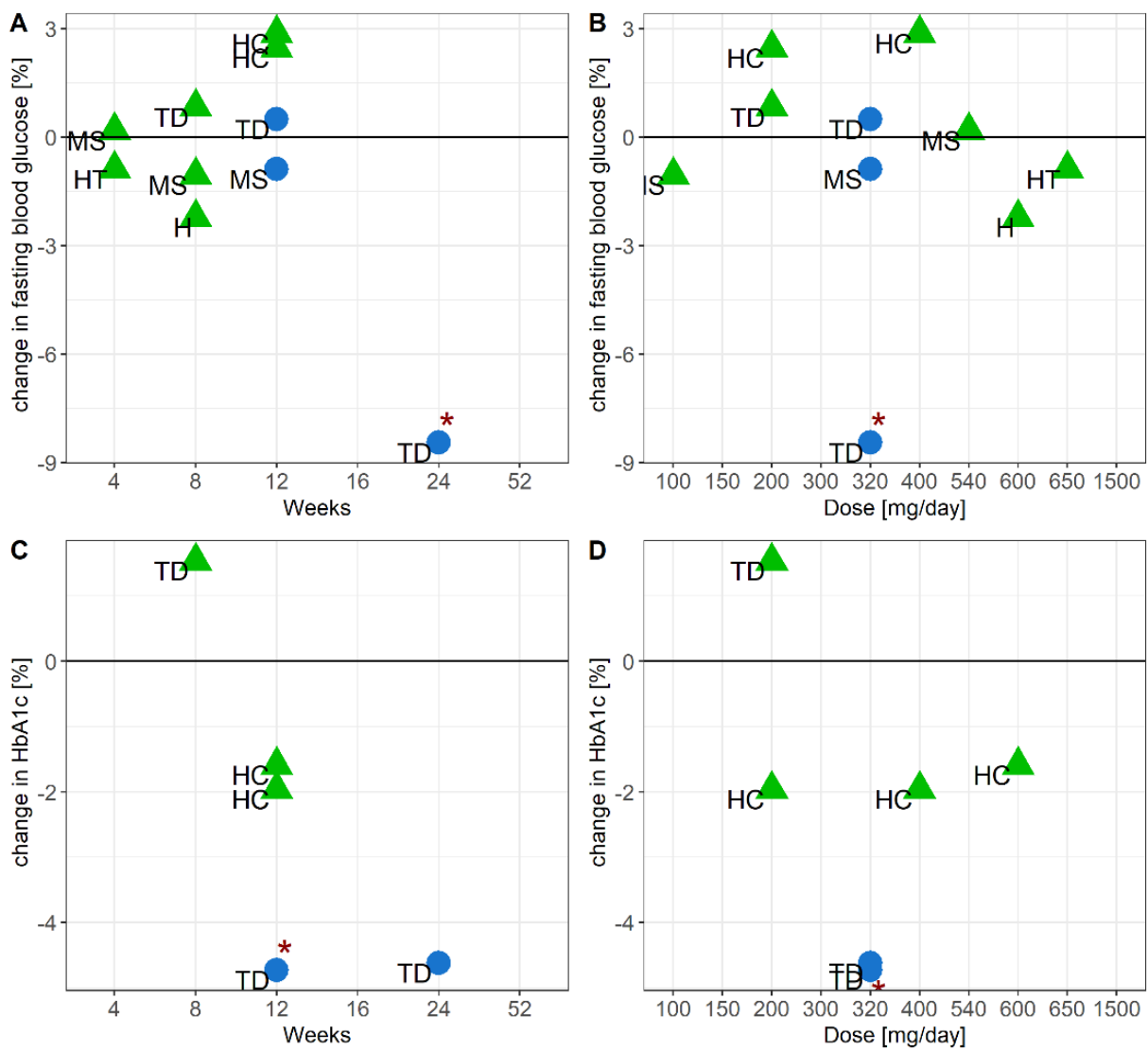

Figure 4. Relationship between the average change in fasting blood glucose and study duration (A), or dose (B), and between the average change in HbA1c levels and study duration (C), or dose (D). $\bullet=$ bilberry and blackcurrant extract (blue), $\boldsymbol{\Delta}$ = grape seed extract (green), study population: $\mathrm{H}=$ healthy, $\mathrm{HC}=$ hypercholesterolemia, $\mathrm{HT}=$ hypertension, $\mathrm{MS}=$ metabolic syndrome, $\mathrm{TD}=$ Type 2 Diabetes Mellitus. ${ }^{*}$ published $p$-value $<0.05$.

\subsection{Efficacy of Grape Seed and Bilberry and Blackcurrant Extract Supplements to Modulate Blood Pressure}

Systolic and diastolic blood pressure was monitored in 17 studies-thirteen with grape seed extract and four with bilberry and blackcurrant extract (Figure 6). Four of the thirteen studies with grape seed extract $[31,34,37,40]$ reported a significant reduction in both systolic and diastolic blood pressure in subjects diagnosed with metabolic syndrome or hypertension, whereas only one study with bilberry and blackcurrant extract reported a significant decrease in systolic blood pressure in subjects with T2DM [43]. Differential responsiveness in systolic and diastolic blood pressure could not be explained by dose or study duration.

3.8. Overall Efficacy of Grape Seed and Bilberry and Blackcurrant Extracts to Modulate Glucose and Cholesterol Metabolism, and Blood Pressure

Figure 7 shows the mean physiological changes in health outcomes upon intervention with either grape seed or bilberry and blackcurrant extract across studies as a means to evaluate their efficacy to modulate health outcomes. Intervention with bilberry and blackcurrant extract reduced $\mathrm{HbA} 1 \mathrm{c}$ by on average $4.7 \%$ and reduced fasting blood glucose levels by on average 3\%, but the variability between studies was large. Intervention with grape seed extract did not notably affect average $\mathrm{HbA1c}$ or fasting blood glucose levels. Both grape seed and bilberry and blackcurrant extract reduced total cholesterol by on average $4.3 \%$ and $3.1 \%$, respectively, and LDL cholesterol levels by on average $6.0 \%$ and $9.8 \%$, respectively. Only interventions with bilberry and blackcurrant extract increased HDL cholesterol levels by on average $7.8 \%$, but the variability between studies was large. 
Both grape seed and bilberry and blackcurrant extracts reduced systolic blood pressure by $5 \%$ and $2.9 \%$, respectively, and diastolic blood pressure by $3.7 \%$ and $1.9 \%$, respectively, but the variability was larger, especially between grape seed extract interventions.
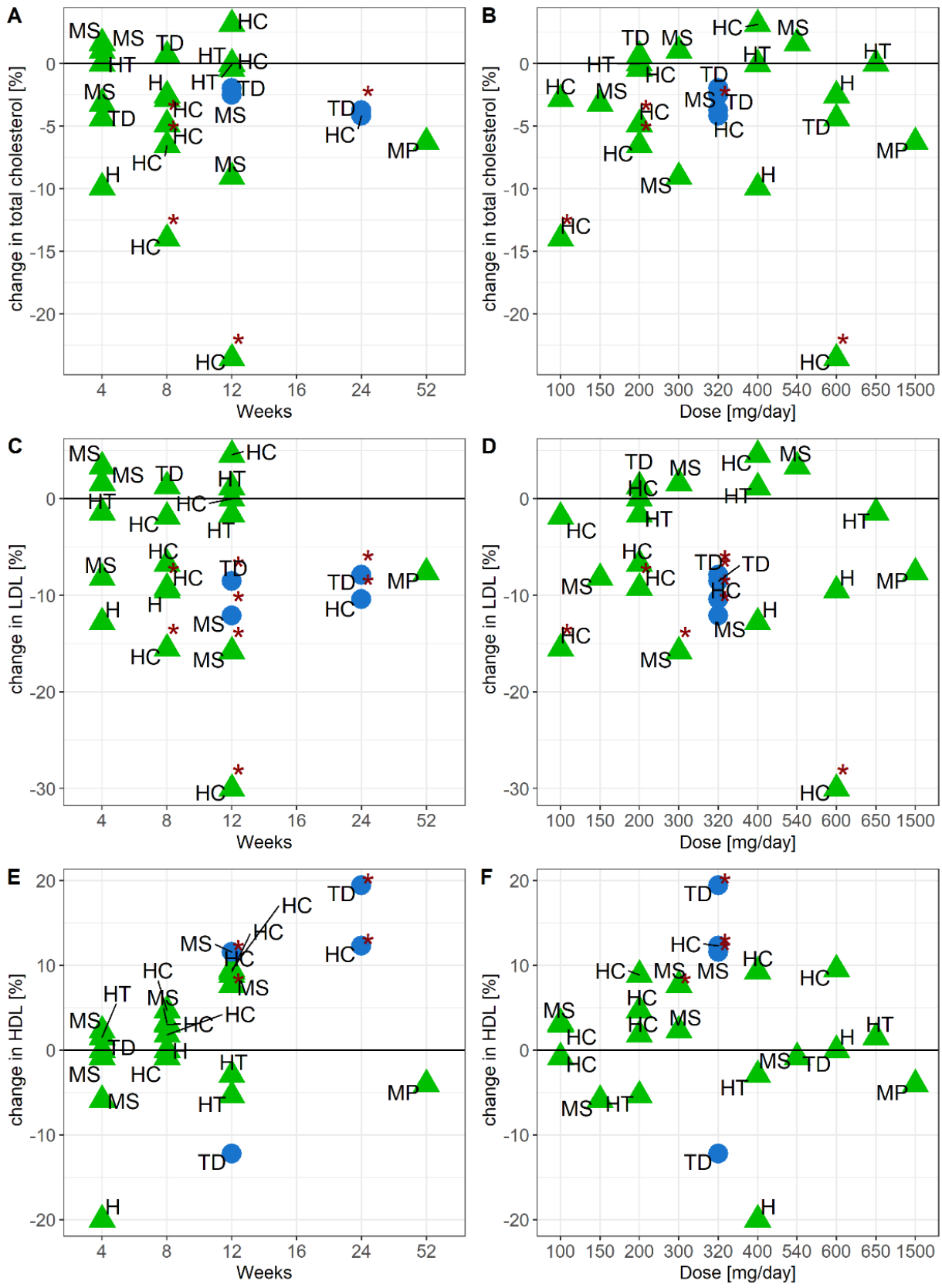

Figure 5. Relationship between total cholesterol and study duration (A), or dose (B), LDL cholesterol and study duration (C), or dose (D), HDL cholesterol and study duration (E), or dose (F). $\bullet=$ bilberry and blackcurrant extract (blue), $\mathbf{\Delta}$ = grape seed extract (green), study population: $\mathrm{H}=$ healthy, $\mathrm{HC}=$ hypercholesterolemia, $\mathrm{HT}=$ hypertension, $\mathrm{MP}=$ mixed postmenopausal, $\mathrm{MS}=$ metabolic syndrome, TD = Type 2 Diabetes Mellitus. ${ }^{*}$ published $p$-value $<0.05$. 

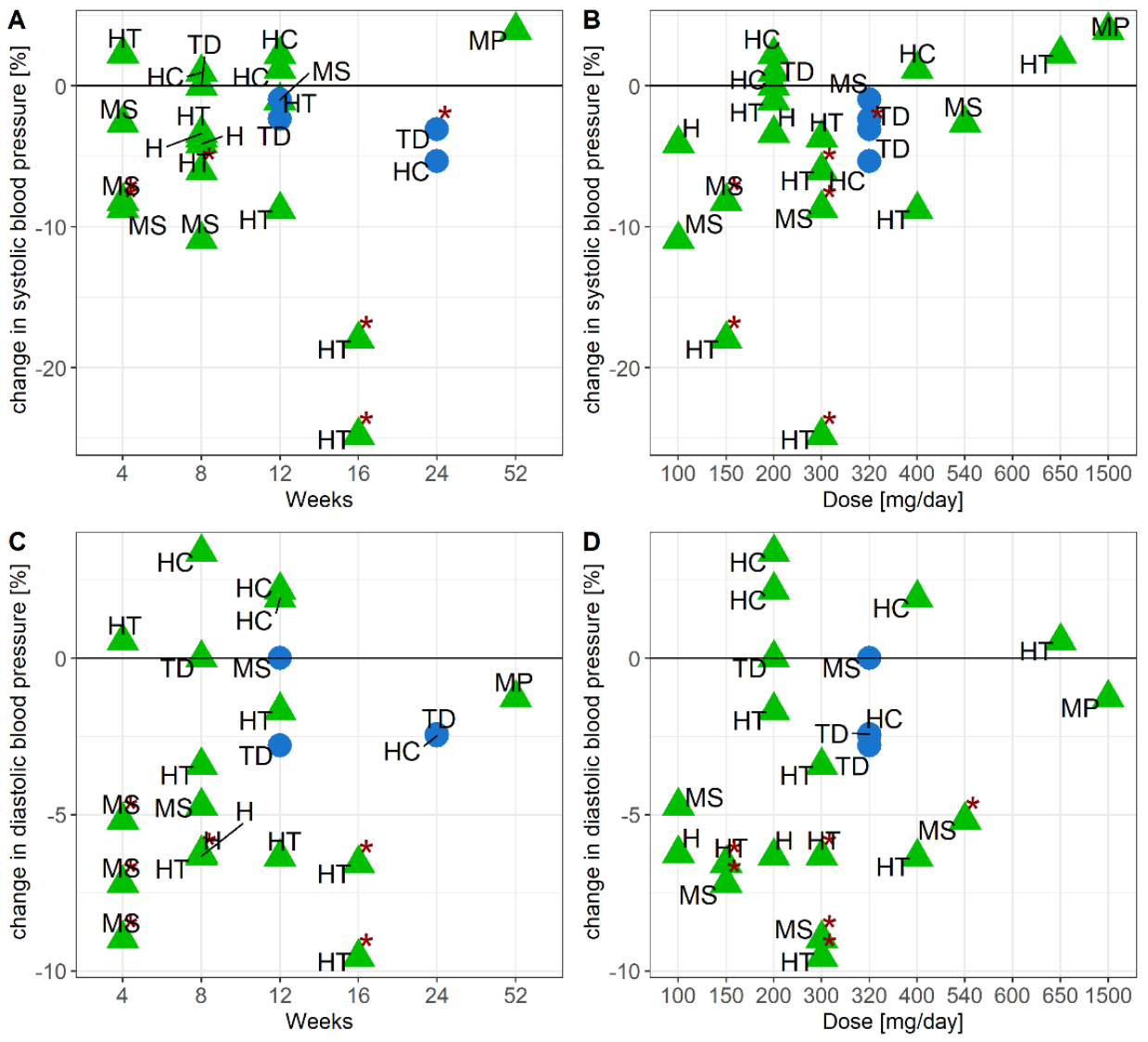

Figure 6. Relationship between systolic blood pressure and study duration (A), or dose (B), diastolic blood pressure and study duration (C) or dose (D). $\bullet=$ bilberry and blackcurrant extract (blue), $\boldsymbol{\Delta}$ = grape seed extract (green), study population: $\mathrm{H}=$ healthy, $\mathrm{HC}=$ hypercholesterolemia, $\mathrm{HT}=$ hypertension, $\mathrm{MP}=$ mixed postmenopausal, $\mathrm{MS}=$ metabolic syndrome, $\mathrm{TD}=$ Type 2 Diabetes Mellitus. ${ }^{*}$ published $p$-value $<0.05$

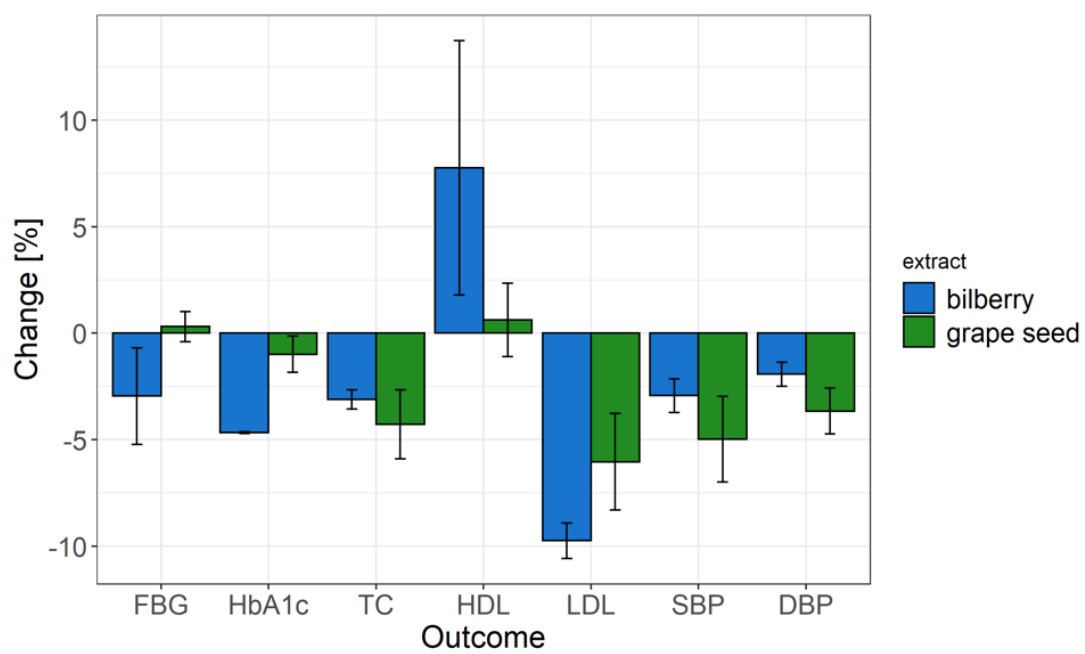

Figure 7. Calculated means and standard errors of percentage changes in study outcomes (FBGfasting blood glucose, HbA1c-glycated hemoglobin, TC—-total cholesterol, HDL and LDL cholesterol, SBP — systolic blood pressure, DBP—diastolic blood pressure) across all intervention studies with bilberry interventions (blue) and grape seed interventions (green). 


\section{Discussion}

We found good evidence that bilberry and blackcurrant extract lowered average levels of $\mathrm{HbA} 1 \mathrm{c}$ in a number of longer-term Chinese studies, in subjects who were older (e.g., $>50$ years) and who were diagnosed with T2DM or pre-diabetes. We also found good evidence that across studies in subjects with hypercholesterolemia, T2DM or metabolic syndrome, intervention with bilberry and blackcurrant extract, and to some extent grape seed extract, for four weeks or longer, significantly improved total and LDL cholesterol levels. In addition, intervention with grape seed extract may reduce systolic and diastolic blood pressure in subjects with hypertension or metabolic syndrome. Differential responsiveness in cholesterol and blood pressure outcomes between stratified populations could not be explained by age, dose or study duration.

Thus far, a number of existing meta-analyses and a systematic review on bilberry and grape seed intervention studies have not been able to shed light on important factors that could modulate responsiveness to intervention between stratified groups of participants. One meta-analysis found that interventions with bilberry extract improved LDL and HDL cholesterol levels in subjects at risk of cardiovascular disease, in subjects with metabolic syndrome and in those with hypercholesterolemia [13], whereas a systematic review concluded that interventions with grape polyphenols did not significantly affect glycemia, insulin sensitivity, cholesterol levels or blood pressure [14]. This was in contrast to a recent meta-analysis suggesting that intervention with grape seed extract decreased LDL cholesterol and triglycerides across studies [15], and another meta-analysis suggesting that grape seed extracts decreased systolic and diastolic blood pressure, especially in subjects with metabolic syndrome and pre-hypertension [16]. Significant differences in applied inclusion and exclusion criteria between reviews in relation to study designs, study populations and outcome parameters led to inclusion of different studies, and therefore to different conclusions.

The approach taken in our critical review allowed, for the first time, the assessment of outcomes across study populations, study duration and dose, and the evaluation of responses for a wider range of outcomes including glucose and cholesterol metabolism, and blood pressure, using a correlation analysis. This enabled a better understanding of who may benefit most from grape seed and bilberry supplements, and why. Across studies, it was less clear whether factors such as intervention, dose, study population or study duration influenced the responsiveness to bilberry and blackcurrant and grape seed extracts in terms of improving total and LDL cholesterol levels, and blood pressure. The limited number of published studies with grape seed or bilberry extracts, and in some cases, questionable study and reporting quality (Figure 2), could lead to spurious conclusions. For instance, the increased likelihood of a strong correlation between glucose and $\mathrm{HbA} 1 \mathrm{c}$ outcomes, with BMI or age, could arise from the small number of studies that reported changes in $\mathrm{HbA} 1 \mathrm{c}$ and fasting glucose in very homogeneous study populations. Indeed, the populations assessed for changes in cholesterol outcomes and blood pressure were more heterogeneous, resulting in weak correlations between outcomes and factors relating to study design and population characteristics. Also, it is to be expected that heterogeneity in the health status of the different study populations would have affected the responsiveness to the extract interventions, with more pronounced benefits expected for those with pre-existing conditions such as T2DM and hypertension, compared with healthy populations $[45,46]$. For this review, we calculated average effects in inherently heterogenous populations, which could potentially lead to a high variability in outcomes [8,47]. Aggregation of raw data and evaluation of personalized data from all studies would have provided a more powerful approach to define responsiveness across stratified populations, which is of great interest when developing the next generation of treatment strategies [8].

In this review we established that longer-term interventions with bilberry and blackcurrant extract may lower $\mathrm{HbA} 1 \mathrm{c}$ in older populations diagnosed with T2DM or prediabetes. In one of the two studies, bilberry and blackcurrant extract caused an average decrease in $\mathrm{HbA} 1 \mathrm{c}$ of 5\% (Figure 4) in patients with pre-diabetes and T2DM [41]. Whilst 
this effect was statistically significant, the efficacy of bilberry and blackcurrant extract to lower $\mathrm{HbA} 1 \mathrm{c}$ was much lower than a reported $16 \%$ reduction in $\mathrm{HbA} 1 \mathrm{c}$ levels after a one-year intervention with metformin in subjects with T2DM [48]. An absolute decrease of $1 \%$ in $\mathrm{HbA} 1 \mathrm{c}$ levels above $5 \%$ has been associated with a $21 \%$ decreased risk for cardiovascular incidences, and a $25 \%$ lower mortality risk [49]. This means that an average absolute decrease of $0.3 \%$ in $\mathrm{HbA} 1 \mathrm{c}$ levels after intervention with bilberry and blackcurrant extract $[41,43]$ represents a $6 \%$ reduction in risk of cardiovascular incidences, and an $8 \%$ lower mortality risk. It could be argued that considering the inter-individual variability in response, the efficacy of bilberry and blackcurrant extract to lower $\mathrm{HbA1c}$ levels may come much closer to that of metformin in a smaller subgroup of 'responders'. In addition, there may be scope for the use of bilberry and blackcurrant extract as an adjuvant for drug-based interventions. In this review we are not able to clarify whether the long-term efficacy of the bilberry and blackcurrant extract to lower $\mathrm{HbA} 1 \mathrm{c}$ levels was due to the bilberry or the blackcurrant extract, or a combination of both. However, an acute study with bilberry extract increased insulin sensitivity and reduced glucose uptake in T2DM patients [50], suggesting that bilberry extract may be, at least partially, responsible for the beneficial effects on glucose metabolism. Similarly, systolic blood pressure decreased by on average $9.3 \mathrm{mmHg}$ across 13 intervention studies with grape seed extract, which is equivalent to a $10 \%$ risk reduction for stroke [51]. This efficacy to reduce systolic blood pressure may make grape seed extract a potential treatment for mild hypertension.

Previous reviews and meta-analyses have compared studies without accounting for differences in intervention formulations, which emerge when working with, for example, fresh berries, berry juices, dealcoholized wine and extracts $[10,13,14]$. Differences in intervention formulations would be expected to affect the bioavailability of polyphenols, similar to the way in which food matrices affect bioavailability, uptake and metabolism [6]. Indeed, dietary fibers, certain minerals and proteins, carbohydrates and fats in meals can inhibit or delay polyphenol bioavailability [6,52]. For example, plasma anthocyanin glycosides peaked at later time point when strawberries were consumed with double cream, whereas plasma anthocyanin glycoside levels were decreased when a strawberry beverage was consumed with breakfast compared to before or after breakfast [6]. In addition to the food matrix, other factors such as timing of consumption, consumption with or without other foods, individual health conditions, enzyme activity and differences in gut microbiota composition are likely to affect polyphenol bioavailability, and thus exposure to the bioactive compounds [6,52]. It has to be noted that for the majority of studies included in this review, the phenolic metabolite composition of the bilberry and blackcurrant extract, or the grape seed extract, were not specified, whilst this information is essential for analyzing the relationship between the intake of supplements and its health effects.

In order to assess the role of individual factors on the responsiveness to bilberry and blackcurrant and grape seed extracts, it is paramount to understand the mechanisms and their impact. Polyphenol compounds from fruits led to an upregulation of GLUT4 glucose transporters in muscle and adipose tissue in animal and in vitro studies, thereby increasing glucose storage, phosphorylation and activation of insulin receptors, which increased insulin sensitivity and signaling, and apoptosis protection of pancreatic $\beta$-cells [53]. Furthermore, glucose transport in a Caco-2 intestinal model was decreased in the presence of glycosylated flavonoids and aglycone polyphenol compounds, suggesting reduced uptake of dietary glucose in the small intestine [54]. Consumption of anthocyanin-rich foods including berries have been associated with a reduction in cardiovascular disease risk, potentially due to mechanisms that improve flow-mediated dilation and vascular function [55]. Anthocyanins and their metabolites appear to regulate different cellular processes involved in vascular function by controlling the activity of cell signaling proteins and transcription factors and modulating gene and miRNA expression, especially in relation to modulation of inflammatory responses and platelet activation [55]. However, the majority of the mechanistic studies do not consider factors that affect transformation, absorption, digestion, metabolism and excretion of anthocyanins in the human body [6]. 
Indeed, a large number of in vitro studies concentrate on extracts, aglycones or parent compounds rather than anthocyanin metabolites derived from microbial metabolism, which are often present in higher concentrations in circulation, and are therefore more likely to contribute to the beneficial health effects of anthocyanin consumption [56]. Epidemiological evidence suggests that consumption of proanthocyanidins may protect, to some extent, against cardiovascular diseases and reduce free radical and peroxidative loads; however, evidence from the in vitro and in vivo studies on the involvement of proanthocyanidins in fat metabolism, obesity, and glucose pathways is currently inconsistent, mostly due to the non-standardized administration of these bioactive compounds [57].

We conclude that bilberry and blackcurrant extract may beneficially affect long-term glucose metabolism, albeit that the current evidence is only supported by a few studies in Chinese subjects with T2DM. Bilberry and blackcurrant extracts, and grape seed extracts, are likely to lower total and LDL cholesterol levels in subjects with metabolic syndrome, T2DM or hypercholesterolemia. More limited evidence suggests that grape seed extract may decrease blood pressure in hypertensive subjects or those with metabolic syndrome. Overall, we observed that based on current data, pre-existing health conditions are the main factors for determining responsiveness to intervention, and long-term interventions appear to be more beneficial for regulation of blood glucose and cholesterol metabolism. Future long-term interventions should focus on measuring responsiveness based on multiple individual factors measured in a more continuous manner, in order to better elucidate which population groups may benefit most from intervention.

Author Contributions: Conceptualization, T.G., N.H., W.R., X.Z. and B.d.R.; analysis, T.G., C.L. and G.H.; writing, T.G., N.H., W.R., B.d.R. All authors have read and agreed to the published version of the manuscript.

Funding: This research was funded by By-Health Co. Ltd., Guangzhou, China. G.H., N.H., W.R., and B.d.R. are funded by the Scottish Government Rural and Environmental Science and Analytical Services (RESAS).

Institutional Review Board Statement: Not applicable.

Informed Consent Statement: Not applicable.

Data Availability Statement: All data are contained within the article.

Conflicts of Interest: B.d.R. is an advisor to the Scientific Advisory Board of By-Health Ltd., Guangzhou, China. By-Health had no role in the design of the study, in the analysis or interpretation of data, in the writing of the manuscript or in the decision to publish the results.

\section{References}

1. World Health Organisation. Global Report on Diabetes; World Health Organisation: Geneva, Switzarland, 2014.

2. Mozaffarian, D. Dietary and Policy Priorities for Cardiovascular Disease, Diabetes, and Obesity. Circulation 2016, 133, 187-225. [CrossRef] [PubMed]

3. Salvadó, M.J.; Casanova, E.; Fernández-Iglesias, A.; Arola, L.; Bladé, C. Roles of proanthocyanidin rich extracts in obesity. Food Funct. 2015, 6, 1053-1071. [CrossRef] [PubMed]

4. Gu, L.; Kelm, M.A.; Hammerstone, J.F.; Beecher, G.; Holden, J.; Haytowitz, D.; Gebhardt, S.; Prior, R.L. Concentrations of Proanthocyanidins in Common Foods and Estimations of Normal Consumption. J. Nutr. 2004, 134, 613-617. [CrossRef] [PubMed]

5. Fraga, C.G. Plant Phenolics and Human Health: Biochemistry, Nutrition and Pharmacology; John Wiley \& Sons, Inc.: Hoboken, NJ, USA, 2009.

6. Williamson, G.; Kay, C.D.; Crozier, A. The Bioavailability, Transport, and Bioactivity of Dietary Flavonoids: A Review from a Historical Perspective. Compr. Rev. Food Sci. Food Saf. 2018, 17, 1054-1112. [CrossRef]

7. Walther, B.; Lett, A.M.; Bordoni, A.; Cobos, L.T.; Nieto, J.A.; Dupont, D.; Danesi, F.; Shahar, D.R.; Echaniz, A.; Re, R.; et al. GutSelf: Interindividual Variability in the Processing of Dietary Compounds by the Human Gastrointestinal Tract. Mol. Nutr. Food Res. 2019, 3, 1-28. [CrossRef]

8. Manach, C.; Milenkovic, D.; van de Wiele, T.; Rodriguez-Mateos, A.; de Roos, B.; Garcia-Conesa, M.T.; Landberg, R.; Gibney, E.R.; Heinonen, M.; Tomás-Barberán, F.; et al. Addressing the inter-individual variation in response to consumption of plant food bioactives: Towards a better understanding of their role in healthy aging and cardiometabolic risk reduction. Mol. Nutr. Food Res. 2017, 61, 1-16. [CrossRef] 
9. Laouali, N.; Berrandou, T.; Rothwell, J.A.; Shah, S.; El Fatouhi, D.; Mancini, F.R.; Boutron-Ruault, M.; Fagherazzi, G. Profiles of polyphenol intake and type 2 diabetes risk in 60,586 women followed for 20 years: Results from the E3N cohort study. Nutrients 2020, 12, 1934. [CrossRef]

10. Chan, S.W.; Tomlinson, B. Effects of bilberry supplementation on metabolic and cardiovascular disease risk. Molecules 2020, 25, 1653. [CrossRef]

11. Calvano, A.; Izuora, K.; Oh, E.C.; Ebersole, J.L.; Lyons, T.J.; Basu, A. Dietary berries, insulin resistance and type 2 diabetes: An overview of human feeding trials. Food Funct. 2019, 10, 6227-6243. [CrossRef]

12. Zhang, L.; Wang, Y.; Li, D.; Ho, C.T.; Li, J.; Wan, X. The absorption, distribution, metabolism and excretion of procyanidins. Food Funct. 2016, 7, 1273-1281. [CrossRef]

13. Zhu, Y.; Miao, Y.; Meng, Z.; Zhong, Y. Effects of Vaccinium Berries on Serum Lipids: A Meta-Analysis of Randomized Controlled Trials. Evid.-Based Complement. Altern. Med. 2015, 1-11. [CrossRef]

14. Woerdeman, J.; van Poelgeest, E.; Ket, J.C.F.; Eringa, E.C.; Serné, E.H.; Smulders, Y.M. Do grape polyphenols improve metabolic syndrome components? A systematic review. Eur. J. Clin. Nutr. 2017, 71, 1381-1392. [CrossRef] [PubMed]

15. Anjom-Shoae, J.; Milajerdi, A.; Larijani, B.; Esmaillzadeh, A. Effects of grape seed extract on dyslipidaemia: A systematic review and dose-response meta-analysis of randomised controlled trials. Br. J. Nutr. 2020, 1-14. [CrossRef]

16. Zhang, L.; Shuang, L.; Lan, L.; Liu, S.; Geng, T. The impact of grape seed extract treatment on blood pressure changes: A meta-analysis of 16 randomized controlled trials. Medicine 2016, 95, 1-7. [CrossRef] [PubMed]

17. Higgins, J.P.; Savović, J.; Page, M.J.; Elbers, R.G.; Sterne, J.A. Assessing risk of bias in a randomized trial. In Cochrane Handbook for Systematic Reviews of Interventions Version 6.1; John Wiley \& Sons: Chichester, UK, 2020; Chapter 8.

18. R Core Team. R: A Language and Environment for Statistical Computing; R Foundation for Statistical Computing: Vienna, Austria, 2020; Available online: https:/ / www.R-project.org/ (accessed on 16 May 2021).

19. Wei, T.; Simko, V. R Package 'Corrplot': Visualization of a Correlation Matrix (Version 0.84). 2017. Available online: https: //rdrrio/cran/corrplot/ (accessed on 11 May 2021).

20. Wickam, H. ggplot2: Elegant Graphics for Data Analysis; Springer International Publishing: Berlin, Germany, 2016.

21. Taghizadeh, M.; Malekian, E.; Memarzadeh, M.R.; Mohammadi, A.A.; Asemi, Z. Grape Seed Extract Supplementation and the Effects on the Biomarkers of Oxidative Stress and Metabolic Profiles in Female Volleyball Players: A Randomized, Double-Blind, Placebo-Controlled Clinical Trial. Iran. Red Crescent Med. J. 2016, 18, 1-9. [CrossRef]

22. Saedomocheshi, S. The effects of regular aerobic training and grape seed extract on the cardiovascular risk factors in obese older women. J. Kurdistan Univ. Med. Sci. 2015, 1, 8-14.

23. Sano, A.; Uchida, R.; Saito, M.; Shioya, N.; Komori, Y.; Tho, Y.; Hashizume, N. Beneficial effects of grape seed extract on malondialdehyde-modified LDL. J. Nutr. Sci. Vitaminol. 2007, 53, 174-182. [CrossRef] [PubMed]

24. Terauchi, M.; Horiguchi, N.; Kajiyama, A.; Akiyoshi, M.; Owa, Y.; Kato, K.; Kubota, T. Effects of grape seed proanthocyanidin extract on menopausal symptoms, body composition, and cardiovascular parameters in middle-aged women: A randomized, double-blind, placebo-controlled pilot study. Menopause 2014, 21, 990-996. [CrossRef]

25. Mellen, P.B.; Daniel, K.R.; Brosnihan, K.B.; Hansen, K.J.; Herrington, D.M. Effect of muscadine grape seed supplementation on vascular function in subjects with or at risk for cardiovascular disease: A randomized crossover trial. J. Am. Coll. Nutr. 2010, 29, 469-475. [CrossRef]

26. Argani, H.; Ghorbanihaghjo, A.; Vatankhahan, H.; Rashtchizadeh, N.; Raeisi, S.; Ilghami, H. O efeito do extrato de semente de uva vermelha na atividade do soro paraoxonase em doentes com hiperlipidemia leve a moderada. Sao Paulo Med. J. 2016, 134, 234-239. [CrossRef]

27. Kasliwal, R.R.; Bansal, M.; Gupta, R.; Shah, S.; Dani, S.; Oomman, A.; Pai, V.; Prasad, G.M.; Singhvi, S.; Patel, J. ESSENS dyslipidemia: A placebo-controlled, randomized study of a nutritional supplement containing red yeast rice in subjects with newly diagnosed dyslipidemia. Nutrition 2016, 32, 767-776. [CrossRef] [PubMed]

28. Preuss, H.G.; Wallerstedt, D.; Talpur, N.; Tutuncuoglu, S.O.; Echard, B.; Myers, A.; Bui, M.; Bagchi, D. Effects of Niacin-bound chromium and Grape seed proanthocyanidin extract on the Lipid Profile of Hypercholesterolemic Subjects. J. Med. 2000, 31, 227-244.

29. Razavi, S.-M.; Gholamin, S.; Eskandari, A.; Mohsenian, N.; Ghorbanihaghjo, A.; Delazar, A.; Rashtchizadeh, N.; Keshtkar-Jahromi, M.; Argani, H. Red Grape Seed Extract Improves Lipid Profiles and Decreases Oxidized Low-Density Lipoprotein in Patients with Mild Hyperlipidemia. J. Med. Food 2013, 16, 255-258. [CrossRef] [PubMed]

30. Zhu, Y.; Ling, W.; Guo, H.; Song, F.; Ye, Q.; Zou, T.; Li, D.; Zhang, Y.; Li, G.; Xiao, Y.; et al. Anti-inflammatory effect of purified dietary anthocyanin in adults with hypercholesterolemia: A randomized controlled trial. Nutr. Metab. Cardiovasc. Dis. 2013, 23, 843-849. [CrossRef] [PubMed]

31. Biesinger, S.; Michaels, H.A.; Quadros, A.S.; Qian, Y.; Rabovsky, A.B.; Badger, R.S.; Jalili, T. A combination of isolated phytochemicals and botanical extracts lowers diastolic blood pressure in a randomized controlled trial of hypertensive subjects. Eur. J. Clin. Nutr. 2016, 70, 10-16. [CrossRef] [PubMed]

32. Mohammad, A.; Shahnaz, T.; Sorayya, K. Effect of 8 weeks' supplementation grape seed extract on insulin resistance in iranian adolescents with metabolic syndrome: A randomized controlled trial. Diabetes Metab. Syndr. Clin. Res. Rev. 2021, 15, 197-203. [CrossRef] 
33. Qin, Y.; Xia, M.; Ma, J.; Hao, Y.; Liu, J.; Mou, H.; Cao, L.; Ling, W. Anthocyanin supplementation improves serum LDL- and HDL-cholesterol concentrations associated with the inhibition of cholesteryl ester transfer protein in dyslipidemic subjects. Am. J. Clin. Nutr. 2009, 90, 485-492. [CrossRef]

34. Sivaprakasapillai, B.; Edirisinghe, I.; Randolph, J.; Steinberg, F.; Kappagoda, T. Effect of grape seed extract on blood pressure in subjects with the metabolic syndrome. Metab. Clin. Exp. 2009, 58, 1743-1746. [CrossRef]

35. Yousefi, R.; Parandoosh, M.; Khorsandi, H.; Hosseinzadeh, N.; Tonekaboni, M.M.; Saidpour, A.; Babaei, H.; Ghorbani, A. Grape seed extract supplementation along with a restricted-calorie diet improves cardiovascular risk factors in obese or overweight adult individuals: A randomized, placebo-controlled trial. Phyther. Res. 2020, 1-9. [CrossRef]

36. Myasoedova, V.; Kirichenko, T.V.; Melnichenko, A.A.; Orekhova, V.A.; Ravani, A.; Poggio, P.; Sobenin, I.A.; Bobryshev, Y.V.; Orekhov, A.N. Anti-Atherosclerotic Effects of a Phytoestrogen-Rich Herbal Preparation in Postmenopausal Women. Int. J. Mol. Sci. 2016, 17, 1318. [CrossRef]

37. Belcaro, G.; Ledda, A.; Hu, S.; Cesarone, M.R.; Feragalli, B.; Dugall, M. Grape seed procyanidins in pre- and mild hypertension: A registry study. Evid.-Based Complement. Altern. Med. 2013, 2013, 1-5. [CrossRef]

38. Odai, T.; Terauchi, M.; Kato, K.; Hirose, A.; Miyasaka, N. Effects of Grape Seed Proanthocyanidin Extract on Vascular Endothelial Function in Participants with Prehypertension: A Randomized, Double-Blind, Placebo-Controlled Study. Nutrients 2019, 11, 2844. [CrossRef] [PubMed]

39. Ras, R.T.; Zock, P.L.; Zebregs, Y.E.M.P.; Johnston, N.R.; Webb, D.J.; Draijer, R. Effect of polyphenol-rich grape seed extract on ambulatory blood pressure in subjects with pre- and stage I hypertension. Br. J. Nutr. 2013, 110, 2234-2241. [CrossRef] [PubMed]

40. Robinson, M.; Lu, B.; Edirisinghe, I.; Kappagoda, C.T. Effect of grape seed extract on blood pressure in subjects with prehypertension. J. Pharm. Nutr. Sci. 2012, 2, 155-159.

41. Yang, L.; Ling, W.; Yang, Y.; Chen, Y.; Tian, Z.; Du, Z.; Chen, J.; Xie, Y.; Liu, Z.; Yang, L. Role of Purified Anthocyanins in Improving Cardiometabolic Risk Factors in Chinese Men and Women with Prediabetes or Early Untreated Diabetes-A Randomized Controlled Trial. Nutrients 2017, 9, 1104. [CrossRef] [PubMed]

42. Kar, P.; Laight, D.; Rooprai, H.K.; Shaw, K.M.; Cummings, M. Effects of grape seed extract in Type 2 diabetic subjects at high cardiovascular risk: A double blind randomized placebo controlled trial examining metabolic markers, vascular tone, inflammation, oxidative stress and insulin sensitivity. Diabet. Med. 2009, 26, 526-531. [CrossRef] [PubMed]

43. Li, D.; Zhang, Y.; Liu, Y.; Sun, R.; Xia, M. Purified Anthocyanin Supplementation Reduces Dyslipidemia, Enhances Antioxidant Capacity, and Prevents Insulin Resistance in Diabetic Patients. J. Nutr. 2015, 145, 742-748. [CrossRef] [PubMed]

44. Pourghassem-Gargari, B.; Abedini, S.; Babaei, H.; Aliasgarzadeh, A.; Pourabdollahi, P. Effect of supplementation with grape seed (Vitis vinifera) extract on antioxidant status and lipid peroxidation in patient with type II diabetes. J. Med. Plants Res. 2011, 5, $2029-2034$.

45. García-Conesa, M.-T.; Chambers, K.; Combet, E.; Pinto, P.; Garcia-Aloy, M.; Andrés-Lacueva, C.; de Pascual-Teresa, S.; Mena, P.; Ristic, A.K.; Hollands, W.J.; et al. Meta-Analysis of the Effects of Foods and Derived Products Containing Ellagitannins and Anthocyanins on Cardiometabolic Biomarkers: Analysis of Factors Influencing Variability of the Individual Responses. Int. J. Mol. Sci. 2018, 19, 694. [CrossRef]

46. Menezes, R.; Rodriguez-Mateos, A.; Kaltsatou, A.; González-Sarrías, A.; Greyling, A.; Giannaki, C.; Andres-Lacueva, C.; Milenkovic, D.; Gibney, E.R.; Dumont, J.; et al. Impact of Flavonols on Cardiometabolic Biomarkers: A Meta-Analysis of Randomized Controlled Human Trials to Explore the Role of Inter-Individual Variability. Nutrients 2017, 9, 117. [CrossRef]

47. Schork, N.J.; Goetz, L.H. Single-Subject Studies in Translational Nutrition Research. Annu. Rev. Nutr. 2017, 37, 395-422. [CrossRef] [PubMed]

48. Schweizer, A.; Couturier, A.; Foley, J.E.; Dejager, S. Comparison between vildagliptin and metformin to sustain reductions in HbA1c over 1 year in drug-naïve patients with Type 2 diabetes. Diabet. Med. 2007, 24, 955-961. [CrossRef]

49. Giugliano, D.; Ceriello, A.; Esposito, K. Glucose metabolism and hyperglycemia. Am. J. Clin. Nutr. 2008, 87, 217-222. [CrossRef] [PubMed]

50. Hoggard, N.; Cruickshank, M.; Moar, K.; Bestwick, C.; Holst, J.J.; Russell, W.; Horgan, G. A single supplement of a standardised bilberry (Vaccinium myrtillus L.) extract (36\% wet weight anthocyanins) modifies glycaemic response in individuals with type 2 diabetes controlled by diet and lifestyle. J. Nutr. Sci. 2013, 2, 1-9. [CrossRef]

51. Lewington, S.; Clarke, R.; Qizilbash, N.; Peto, R.; Collins, R. Age-specific relevance of usual blood pressure to vascular mortality: A meta-analysis of individual data for one million adults in 61 prospective studies. Lancet 2002, 360, 1903-1913. [PubMed]

52. Bohn, T. Dietary factors affecting polyphenol bioavailability. Nutr. Rev. 2014, 72, 429-452. [CrossRef]

53. Babu, P.V.A.; Liu, D.; Gilbert, E.R. Recent advances in understanding the anti-diabetic actions of dietary flavonoids. J. Nutr. Biochem. 2013, 24, 1777-1789. [CrossRef]

54. Johnston, K.; Sharp, P.; Clifford, M.; Morgan, L. Dietary polyphenols decrease glucose uptake by human intestinal Caco-2 cells. FEBS Lett. 2005, 579, 1653-1657. [CrossRef]

55. Wood, E.; Hein, S.; Heiss, C.; Williams, C.; Rodriguez-Mate, A. Blueberries and cardiovascular disease prevention. Food Funct. 2019, 10, 7621-7633. [CrossRef]

56. Krga, I.; Milenkovic, D. Anthocyanins: From Sources and Bioavailability to Cardiovascular-Health Benefits and Molecular Mechanisms of Action. J. Agric. Food Chem. 2019, 67, 1771-1783. [CrossRef]

57. Nie, Y.; Stürzenbaum, S.R. Proanthocyanidins of Natural Origin: Molecular Mechanisms and Implications for Lipid Disorder and Aging-Associated Diseases. Adv. Nutr. 2019, 10, 464-478. [CrossRef] [PubMed] 